\title{
miRNA-140 inhibits C3H10T1/2 mesenchymal stem cell proliferation by targeting CXCL12 during transforming growth factor- $\beta 3$-induced chondrogenic differentiation
}

\author{
QINGDE WA $^{1}$, YI LIU ${ }^{1}$, SHUAI HUANG ${ }^{2}$, PEIHENG HE $^{2}$, JIANWEI ZUO ${ }^{3}$, \\ XING LI ${ }^{2}$, ZIQING LI ${ }^{2}$, LIMING DONG ${ }^{1}$, JIACHEN PENG ${ }^{1}$, SHUHONG WU ${ }^{1}$, \\ FANG CHEN $^{1}$, DONGFENG CAI ${ }^{1}, \mathrm{XUENONG} \mathrm{ZOU}^{2}$ and WENBO LIAO ${ }^{1}$
}

\begin{abstract}
${ }^{1}$ Department of Orthopedic Surgery, The First Affiliated Hospital of Zunyi Medical College, Zunyi, Guizhou 563003;
${ }^{2}$ Department of Orthopedic Surgery, The First Affiliated Hospital of Sun Yat-sen University, Guangzhou, Guangdong 510080;

${ }^{3}$ Department of Sports Medicine, Shenzhen Hospital of Peking University, Shenzhen, Guangdong 518036, P.R. China
\end{abstract}

Received March 7, 2016; Accepted March 10, 2017

DOI: $10.3892 / \mathrm{mmr} .2017 .6720$

\begin{abstract}
The aim of the present study was to investigate the role of microRNA (miRNA or miR)-140 in C3H10T1/2 mesenchymal stem cells (MSCs). Cluster analysis was used to evaluate the miRNA expression profile. The expression level of miRNA-140 was validated by reverse transcription-quantitative polymerase chain reaction (RT-qPCR). TargetScan and microRNA.org databases were used to predict target miRNAs and cartilage-associated target genes. Binding sites between miR-140 and the target gene were predicted by bioinformatics software. A dual-luciferase reporter assay was performed to determine whether miR-140 could target C-X-C motif chemokine ligand 12 (CXCL12). Following the promotion/inhibition of miR-140, 1, 7 and 14 days following transforming growth factor- $\beta 3$ (TGF- $\beta 3$ )-induction, western blotting was utilized to evaluate CXCL12 protein levels. MTT assays and alcian blue staining were applied to assess C3H10T1/2 MSC viability and chondrogenic differentiation, respectively. In the TGF- $\beta 3$-induced group, RT-qPCR verified that the mRNA level of Mus musculus (mmu)-miR-140 was significantly elevated when compared with the control group. miR-140 was predicted to recognize and interact with CXCL12-3'UTR and the dual luciferase reporter assay further validated that miR-140 targeted the predicted region of CXCL12. CXCL12 was markedly decreased following miR-140 overexpression and visibly increased following miR-140 inhibition. In addition, the level of CXCL12 expression declined as the duration of induction increased. Following the promotion/inhibition
\end{abstract}

Correspondence to: Professor Wenbo Liao, Department of Orthopedic Surgery, The First Affiliated Hospital of Zunyi Medical College, 201 Dalian Road, Zunyi, Guizhou 563003, P.R. China

E-mail: liaowenbogz@sina.com

Key words: microRNA-140, chondrogenic differentiation, C-X-C motif chemokine ligand 12 of miR-140, at 1 and 7 days following TGF- $\beta 3$-induction, C3H10T1/2 MSCs inhibited or promoted cell viability, respectively, when compared with the control groups. In addition, in pellets achieved by chondrogenic differentiation following the induction of C3H10T1/2 MSCs for 7 days, alcian blue staining revealed no significant difference in characteristic extracellular matrix glycosaminoglycans between the miR-140 up and downregulated groups, and their respective control groups. The present study concludes that miRNA-140 inhibition promoted C3H10T1/2 MSC viability however, not $\mathrm{C} 3 \mathrm{H} 10 \mathrm{~T} 1 / 2 \mathrm{MSC}$ differentiation by targeting and reducing CXCL12 protein levels during the process of TGF- $\beta 3$-induced chondrogenic differentiation. In conclusion, the present study provided a potential target for the treatment of cartilage defection.

\section{Introduction}

It is well established that joint function is seriously impaired by cartilage defection, in fact even very small defects in cartilage are difficult to repair due to the lack of self-repair ability (1). Mesenchymal stem cells (MSCs) are thought to be an ideal target for repairing defective cartilage on account of their self-repair ability, multidirectional differentiation potential and low immunogenicity (2). One type of MSC line derived from mouse embryos known as the C3H10T1/2 cell line has been widely applied in research that focused on the differentiation and regulation of stem cells (3). Bone morphogenic protein 4 (BMP4) treatment may induce C3H10T1/2 stem cells to commit to the adipocyte lineage (4). In addition, curculactones, A or B, increase the expression of osteogenic marker genes and alkaline phosphatase activity, leading to the differentiation of the mesenchymal cell line C3H10T1/2 (5). Our previous research demonstrated that transforming growth factor $\beta 3$ (TGF- $\beta 3$ ) induced C3H10T1/2 MSC line differentiation (6). Therefore, an in vitro chondrogenic differentiation model for MSCs would be of value in the promotion of MSC chondrogenic differentiation prior to transplantation. However, the underlying mechanism requires further clarification. 
microRNA (miRNA or miR), a type of non-coding small RNA 22 nucleotides in length, is found extensively in eukaryons. The biological functions of miRNA are diverse; for example, one miRNA may modulate a number of different target genes and one target gene may be coregulated by several miRNAs (1). miRNA has become an important tool in genetic engineering as it is small, specific and endogenous. An increasing body of evidence has demonstrated that miRNA can alter stem cell fates and modulate the underlying epigenetics in biological behavior (7-10). It has been reported that miR-29a is essential for the differentiation of MSCs by regulating forkhead box O3 expression (11). Upregulation of 573-3p by SRY-Box 9 may inhibit retinoid X receptor-a expression and chondrogenic differentiation of MSCs (12). In addition, miR-144-3p acts as a negative regulator of osteogenic differentiation and proliferation in $\mathrm{C} 3 \mathrm{H} 10 \mathrm{~T} 1 / 2$ cells and mothers against decapentaplegic homolog 4 serves as its specific target gene (13). miR-125b serves as a key regulatory factor of osteoblastic differentiation by directly targeting core-binding factor b in C3H10T1/2 cells (14). These results indicated that miRNAs may take part in the process of $\mathrm{C} 3 \mathrm{H} 10 \mathrm{~T} 1 / 2$ cell differentiation or proliferation. A previous report revealed that microRNA-140 (miR-140) served an important role in BMP4-induced C3H10T1/2 pluripotent stem cells in achieving commitment to the adipocyte lineage (15). miR-140 overexpression promotes this process, whereas knockdown miR-140 generates the opposite result by targeting the osteopetrosis associated transmembrane protein 1 gene (15). BMP4 and TGF- $\beta 3$ are also involved in the process of $\mathrm{C} 3 \mathrm{H} 10 \mathrm{~T} 1 / 2$ cell differentiation (6), however, whether miR-140 could serve as a direct downstream component of TGF- $\beta 3$ during $\mathrm{C} 3 \mathrm{H} 10 \mathrm{~T} 1 / 2$ cell differentiation requires further study. In the present study, the effect of miR-140 in TGF- $\beta 3$-induced C3H10T1/2 cell differentiation is analyzed.

C-X-C motif chemokine 12 (CXCL12) is encoded by the CXCL12 gene and belongs to the chemokine family. It can active leukocytes and is often induced by proinflammatory stimuli including lipopolysaccharides, tumor necrosis factors or interleukin-1. CXCL12 is a widely expressed gene and has an extensive role in muscle, neural, liver and tissue repair $(16,17)$. A previous study revealed that CXCL12 is a regulator of osteogenic differentiation induced by BMP2 (18). In addition, CXCL12/CXCR4 significantly affected early and mid-osteogenic marker expression in C3H10T1/2 cells (19). These findings indicated that the CXCL12/CXCR4 signal axis effects the BMP9-induced osteogenic differentiation of MSCs. Therefore, CXCL12 may serve an important role in osteogenic differentiation. Currently, the number of studies investigating the miRNA regulation of CXCL12 in C3H10T1/2 is relatively low. Thus, the present study evaluated the underlying mechanism of how miR-140 regulates expression.

The precise molecular mechanism underlying chondrogenic differentiation in stem cells remains elusive. The aim of the present study was to provide a theoretical foundation for the role of potential miRNAs in C3H10T1/2 MSC.

\section{Materials and methods}

Cell culture and preparation of cell pellets. C3H10T1/2 MSCs were purchased from American Type Culture Collection
(Manassas, VA, USA), cultured in low-glucose Dulbecco's modified Eagle's medium (DMEM; Thermo Fisher Scientific, Inc., Waltham, MA, USA) supplemented with $10 \%$ fetal bovine serum (FBS; Thermo Fisher Scientific, Inc.) and were then incubated at a $37^{\circ} \mathrm{C}$ and $95 \%$ humidity. Once $90 \%$ confluence was achieved, $\mathrm{C} 3 \mathrm{H} 10 \mathrm{~T} 1 / 2 \mathrm{MSC}$ were generated in a 1:6 dilution. The passage 7 generation of C3H10T1/2 MSCs was digested with $0.25 \%$ trypsin (Invitrogen; Thermo Fisher Scientific, Inc.) and divided into 2 groups: The non-induced group (culture medium contained $500 \mathrm{ml}$ high-glucose DMEM and $10 \mathrm{ml} \mathrm{FBS}$ ) and the TGF- $\beta 3$-induced group (culture medium contained $500 \mathrm{ml}$ high-glucose DMEM, $5 \mu \mathrm{g}$ TGF- $\beta 3,0.15 \mathrm{~g}$ vitamin $\mathrm{C}, 50 \mu \mathrm{l}$ dexamethasone, $0.5 \mathrm{ml}$ Insulin/Transferrin/Selenium solution and $10 \mathrm{ml} \mathrm{FBS}$ ). Cells were suspended and reseeded in $2 \mathrm{ml}$ DMEM at a density of $2.5 \times 10^{5} / \mathrm{ml}$. DMEM $(1 \mathrm{ml})$ was replaced every 2 to 3 days for $\sim 14$ days to generate in vitro pellets.

Verifying differentially expressed miR-140 using reverse transcription-quantitative polymerase chain reaction $(R T-q P C R)$. RNA was reverse transcribed into cDNA using the reverse transcriptase from the PrimeScript reverse transcription reagent kit (Takara Biotechnology Co., Ltd., Dalian, China) according to the manufacturer's instructions. The qPCR reaction mixture included SYBR Premix Ex Taq ${ }^{\mathrm{TM}}$ II (Bio-Rad Laboratories, Inc., Hercules, CA, USA) as well as $2 \mu \mathrm{l}$ cDNA, $5 \mu 12 \mathrm{X}$ master mix, $0.5 \mu \mathrm{l}$ forward primer, $0.5 \mu 1$ reverse primer and $2 \mu \mathrm{l}$ nanopure water to generate a final volume of $10 \mu \mathrm{l}$. Conditions for amplification were as follows: Initial denaturation at $95^{\circ} \mathrm{C}$ for $30 \mathrm{sec}$, then 40 cycles of $10 \mathrm{sec}$ at $95^{\circ} \mathrm{C}$ and $60 \mathrm{sec}$ at $60^{\circ} \mathrm{C}$, and final extension at $72^{\circ} \mathrm{C}$ for $5 \mathrm{~min}$. Experiments were performed with 3 replicates. The U6 gene was used as an endogenous control to normalize differences in the amount of total RNA from each sample. The primer sequences were as follows: Mus musculus (mmu)-miR-140, forward 5'-GCGGCGGCAGTGGTTTTACCC-3' and reverse 5'-ATCCAGTGCAGGGTCCGAGG-3'; and U6, forward 5'-GCTTCGGCAGCACATATACTAAAAT-3' and reverse 5'CGCTTCACGAATTTGCGTGTCAT-3'. The results were calculated using the $2^{-\Delta \Delta C q}$ method was performed using $30 \mu \mathrm{l}$ Lipofectamine 2000 reagent (Invitrogen; Thermo Fisher Scientific, Inc.) according to the manufacturer's instructions. Cell transfection was performed at room temperature.

Western blot analysis. To determine the expression profiles of glyceraldehyde 3-phosphate dehydrogenase (GAPDH) and CXCL12, C3H10T1/2 MSC extract lysates were collected and analyzed. Briefly, samples were washed with ice-cold phosphate-buffered saline (PBS) and homogenized in radioimmunoprecipitation lysis buffer at $4^{\circ} \mathrm{C}$ for $30 \mathrm{~min}$ which contained a cocktail of protease inhibitors and phosphatase inhibitors (Roche Diagnostics, Shanghai, China), and the lysates were collected following high-speed centrifugation $(12,700 \mathrm{x} \mathrm{g})$ for $5 \mathrm{~min}$ at $4^{\circ} \mathrm{C}$. Proteins were then separated by 10\% SDS-PAGE (Roche Diagnostics) and electrotransferred onto polyvinylidene fluoride membranes (EMD Millipore, Billerica, MA, USA). Membranes were blocked in 5\% bovine serum albumin (Invitrogen; Thermo Fisher Scientific, Inc.) for $1 \mathrm{~h}$ at room temperature prior to overnight incubation at $4{ }^{\circ} \mathrm{C}$ with $\alpha$-tubulin (dilution, 1:2,000; cat. no. ab7291; 
Abcam, Cambridge, UK) and CXCL12 (dilution, 1:1,000; cat. no. 5712; Cell Signaling Technology, Inc., Danvers, MA, USA) primary antibodies. Following washing with TBST (TBS with $20 \%$ Tween-20), membranes were incubated with the corresponding rabbit anti-mouse HRP-conjugated IgG (dilution, 1:2,000; cat. no. A16160; Thermo Fisher Scientific, Inc.) for $1 \mathrm{~h}$ at room temperature. Target proteins were visualized using the SuperSignal ${ }^{\circledR}$ West Pico Chemiluminescent Substrate (Thermo Fisher Scientific, Inc.) and $\alpha$-tubulin was used as a loading control.

MTT assay. C3H10T1/2 MSCs were transfected with miR-NC mimics, miR-140 mimics, miR-NC inhibitor or miR-140 inhibitor, followed by TGF- $\beta 3$ induction. After 1 and 7 days, cell viability was measured by MTT assay. Cells $(\sim 200 \mu \mathrm{l}$ at $1 \times 10^{4} / \mathrm{ml}$ ) were seeded into 96 well plates. Following $24 \mathrm{~h}$ incubation, $20 \mu \mathrm{l}$ of $5 \mathrm{mg} / \mathrm{ml}$ MTT solution was added to each well and the plate was further incubated at $37^{\circ} \mathrm{C}$ for $4 \mathrm{~h}$. The medium was then aspirated, the wells were washed with PBS and allowed to dry for $\sim 4 \mathrm{~h}$, and then $150 \mu \mathrm{l}$ DMSO was added to each well. The microtitre plate was placed on a shaker in order to dissolve the dye. Absorbance was read at $490 \mathrm{~nm}$ using a Bio-Rad iMark plate reader (Bio-Rad Laboratories, Inc.).

Alcian blue staining. Cell pellets were fixed with $4 \%$ paraformaldehyde in $0.1 \mathrm{M}$ PBS for $20 \mathrm{~min}$ at $37^{\circ} \mathrm{C}$ and then rinsed with PBS three times. The pellets were dehydrated using a gradient of ethanol $(30,50,70,85,95$ and $100 \%)$, placed in dimethylbenzene for $5 \mathrm{~min}$, embedded with paraffin and sectioned into $4 \mu \mathrm{m}$ thick slices. These sections were stained with $1 \%$ alcian blue dissolved in $3 \%$ acetic acid (ph 2.5) for $10 \mathrm{~min}$ at $37^{\circ} \mathrm{C}$ to quantify glycosaminoglycan (GAG) synthesis. Sections were then washed with water three times and sealed with dry neutral resins. Images were captured on a light microscope (Nikon Eclipse Ci; Nikon Corporation, Tokyo, Japan), and analyzed using Photoshop software CS6 (Adobe CS5; Adobe Systems, Inc., San Jose, CA, USA).

Bioinformatic and statistical analysis. Prediction of miRNA target sites was performed using TargetScan (http:/www. targetscan.org) and microRNA.org (http://www.microrna. org). Differences among groups were analyzed by performing a two-way analysis of variance, followed by Bonferroni post hoc tests using the statistical software IBM SPSS version 21 (IBM Corp., Armonk, NY, USA). Data are presented as the mean \pm standard error mean of 3 repeated experiments. $\mathrm{P}<0.05$ was considered to indicate a statistically significant difference.

\section{Results}

Verification of miR-140 expression levels using RT-qPCR. mmu-miR-140 was analyzed using RT-qPCR to determine its different expression levels. The results of this analysis were consistent with those observed in our microarray analysis performed previously (data not published). In the TGF- $\beta 3$-induced group, mmu-miR-140 was significantly upregulated compared with the non-induced group (Fig. 1).

Target action site of miR-140 on CXCL12 prediction via bioinformatics. TargetScan (http://www.targetscan.org) and

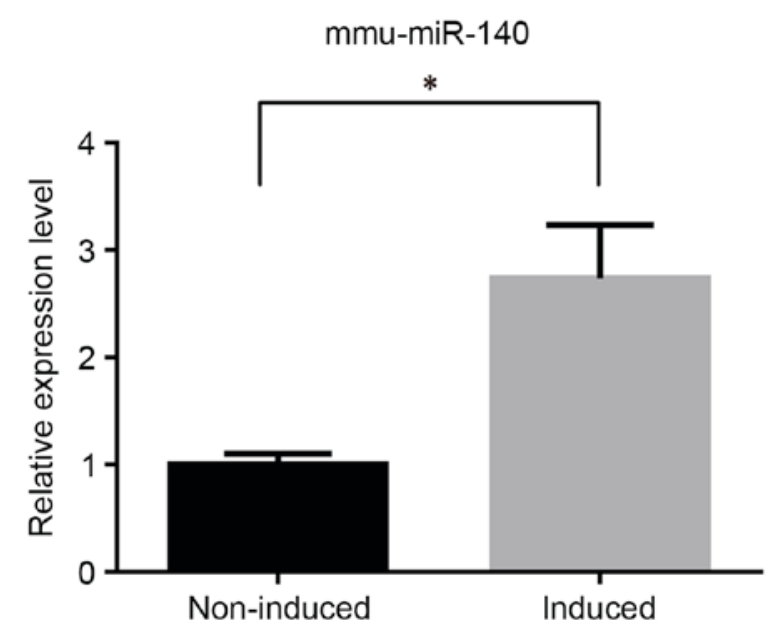

Figure 1. Relative expression of mmu-miR-140. Reverse transcriptionquantitative polymerase chain reaction was used to determine the expression of mmu-miR-140 with/without TGF- $\beta 3$-induced chondrogenic differentiation. ${ }^{*} \mathrm{P}<0.05$, with comparisons indicated by brackets. mmu-miR-140, Mus musculus microRNA-140.

mmu-miR-140/CXCL12 alignment

\begin{tabular}{|c|c|c|}
\hline $\begin{array}{l}\text { mmu-miR-140 } \\
\text { CXCL12 } 1578\end{array}$ & $\begin{array}{c}\text { 3' gaUGGUAUCC - CAUUUUGGUGAC 5' } \\
: \|||:|||||||||| \\
\text { 5' cuGCCCUGAGUUGGAAGACCACUu 3' }\end{array}$ & $\begin{array}{ll}\text { mirSVR score: } & -0.0006 \\
\text { PhastCons score: } & 0.5240\end{array}$ \\
\hline
\end{tabular}

CXCL12 1578 5' cuGCCCUGAGUUGGAAGACCACUu 3' PhastCons score: 0.5240

Figure 2. Binding site between miR-140 and the target gene. miR, microRNA; CXCL12, C-X-C motif chemokine ligand 12; mmu, Mus musculus.

microRNA.org (http://www.microrna.org) databases were used to predict target miRNAs and cartilage-associated target genes. Genes that exhibited relatively higher grades in the two databases were selected as key genes. In our previous study, miR-140 was identified as one of the miRNAs with an altered expression in the TGF- $\beta 3$-induced chondrogenic group (data not published). Thus, in combination with the results of the microarray analysis, miR-140 was chosen as the target of the present study. It was predicted that miR-140 may recognize and interact with the 3' untranslated region (3'UTR) of CXCL12 as presented in Fig. 2.

Interaction between $\mathrm{miR}-140$ and the predicted region of CXCL12. The dual luciferase reporter assay demonstrated that miR-140 mimics significantly inhibited the fluorescence of the CXCL12-WT group when compared with the miR-NC group $(\mathrm{P}<0.05$; Fig. 3A). However, there was no significant difference in fluorescence between the CXCL12-mutant (mut) group and miR-NC group ( $\mathrm{P}>0.05$; Fig. 3B).

CXCL12 protein levels in the different groups analyzed by western blotting. C3H10T1/2 MSCs were transfected with miR-140 mimics or inhibitor in the experimental groups, and transfected with miR-NC mimics or inhibitor in control group, and chondrogenic differentiation was induced by TGF- $\beta 3$. CXCL12 protein levels were assessed by western blotting at 1,7 and 14 days following TGF- $\beta 3$ induction (Fig. 4). CXCL12 was markedly decreased when miR-140 was overexpressed compared with NC (Fig. 4A), however, it was markedly increased when miR-140 expression was inhibited 

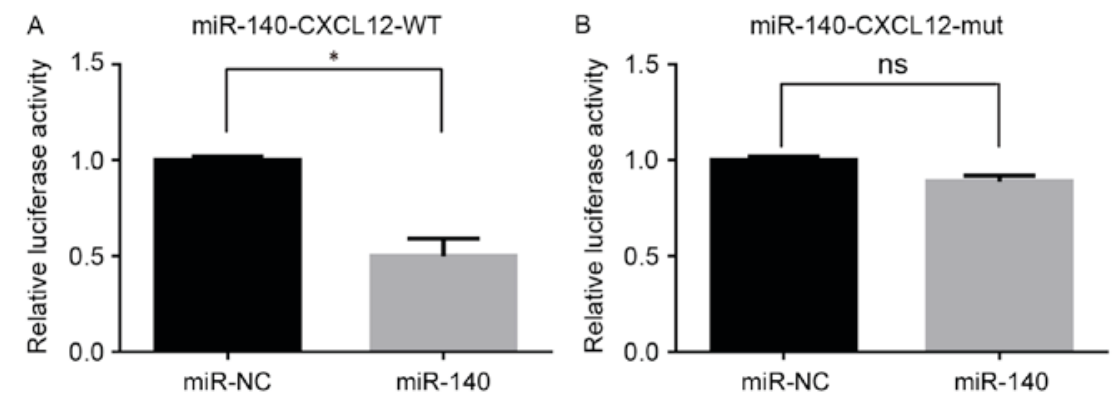

Figure 3. Dual luciferase reporter assay. Relative luciferase activity with (A) WT and (B) mut CXCL12. ${ }^{\text {ns }} \mathrm{P}>0.05$ and ${ }^{*} \mathrm{P}<0.05$, with comparisons indicated by brackets. miR, microRNA; WT, wild-type; mut, mutant; CXCL12, C-X-C motif chemokine ligand 12; NC, negative control.

compared with NC (Fig. 4B). In addition, CXCL12 expression levels declined as the length of the experiment increased in the control and experimental groups (Fig. 4).

C3H10T1/2 MSC cell viability following up-/downregulation of miR-140. At 1 and 7 days following transfection and TGF- $\beta 3$ induction, C3H10T1/2 MSCs transfected with miR-140 mimics exhibited significant inhibition of cell viability compared with $\mathrm{NC}(\mathrm{P}<0.05$; Fig. $5 \mathrm{~A})$. However, those transfected with the miR-140 inhibitor exhibited a significant increase in cell viability compared with the control group (P<0.05; Fig. 5B).

Analysis of GAG synthesis using alcian blue staining. In cell pellets generated by chondrogenic differentiation following the induction of $\mathrm{C} 3 \mathrm{H} 10 \mathrm{~T} 1 / 2$ for 7 days, there was no visible difference in alcian blue staining between the miR-140 up-/downregulation and control groups (Fig. 6).

\section{Discussion}

Microarray analysis demonstrated that, in the TGF- $\beta 3$-induced group, miR-140 expression levels were significantly higher than those observed in the control group. Further analysis using bioinformatics prediction and a dual luciferase assay validated that CXCL12 was the target gene of miR-140. C3H10T1/2 MSCs were transfected with miR-140 mimics or miR-NC mimics, followed by TGF- $\beta 3$ induction. Western blotting after 1,7 and 14 days revealed that CXCL12 was markedly downregulated as a result of miR-140 overexpression. By contrast, CXCL12 was significantly upregulated when miR-140 was inhibited. In addition, the expression of CXCL12 decreased as the length of the experiment increased. Following TGF- $\beta 3$ induction, at 1 and 7 days after transfection, C3H10T1/2 MSCs transfected with miR-140 mimics exhibited reduced cell viability, whereas, those transfected with the miR-140 inhibitor displayed increased cell viability when compared with the control groups. In cell pellets generated by the induction of $\mathrm{C} 3 \mathrm{H} 10 \mathrm{~T} 1 / 2$ MSCs for 7 days, no visible difference in GAG synthesis was observed between the miR-140 up-/downregulation and control groups.

To the best of our knowledge, these results demonstrate for the first time that during the process of TGF- $\beta 3$-induced chondrogenic differentiation, miR-140 inhibits C3H10T1/2 MSC viability by targeting CXCL12, however, there it has no significant influence on $\mathrm{C} 3 \mathrm{H} 10 \mathrm{~T} 1 / 2 \mathrm{MSC}$ differentiation.

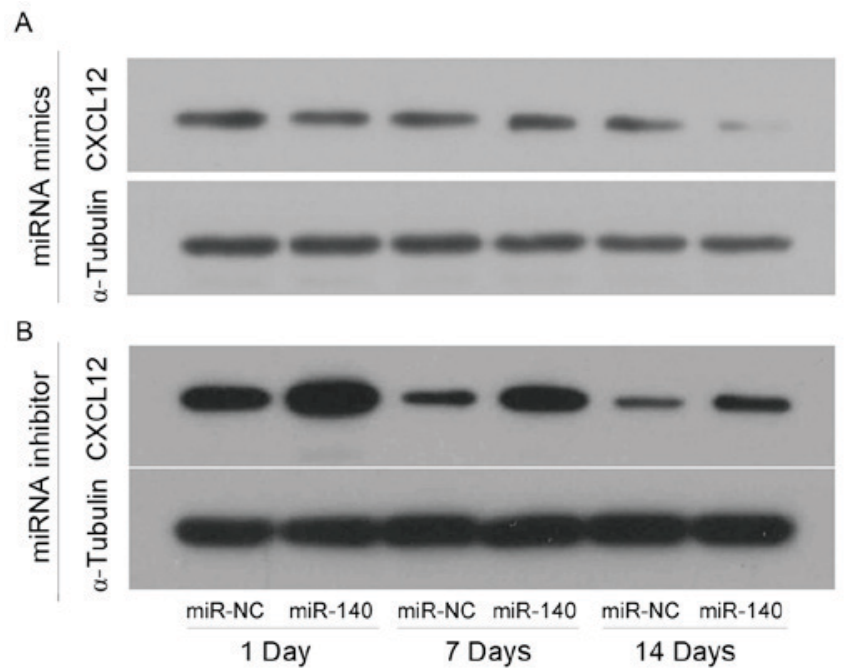

Figure 4. Protein expression levels of CXCL12 with (A) miR-140 mimics and (B) miR-140 inhibitor were examined by western blotting. $\alpha$-Tubulin was used as a loading control. CXCL12, C-X-C motif chemokine ligand 12; miR, microRNA; NC, negative control.

As a member of non-coding RNA family, which are a type of endogenous regulatory RNA, miRNA consists of $\sim 21$ to 23 nucleotides. An increasing body of evidence has indicated that miRNA may participate in a number of physiological and pathological processes, including development, cell differentiation, metabolism and cancer $(9,10,20,21)$. miR-140 is expressed in cartilage tissue and serves an important role in proliferation and differentiation $(22,23)$. In the present study, microarray analysis and RT-qPCR demonstrated that miR-140 is upregulated in TGF- $\beta 3$-induced C3H10T1/2 MSCs. Following this result, the aim was to further clarify the biological role and target gene of miR-140.

Firstly, online software was used to predict the target gene of miR-140 and the interaction site between miR-140 and its target gene. A dual luciferase reporter assay was performed to validate that miR-140 could recognize and interact with CXCL12-3'UTR. As the target gene of miR-140, CXCL12 is also known as stromal cell-derived factor-1 (SDF-1) (24). CXCL12 has been reported to serve a number of biological functions, including bone-marrow myelopoiesis (25), organogenesis and tumorigenesis (26). Kanbe et al (27) indicated that SDF-1 may participate in the destruction of cartilage in osteoarthritis and rheumatoid arthritis. The present study further 
A

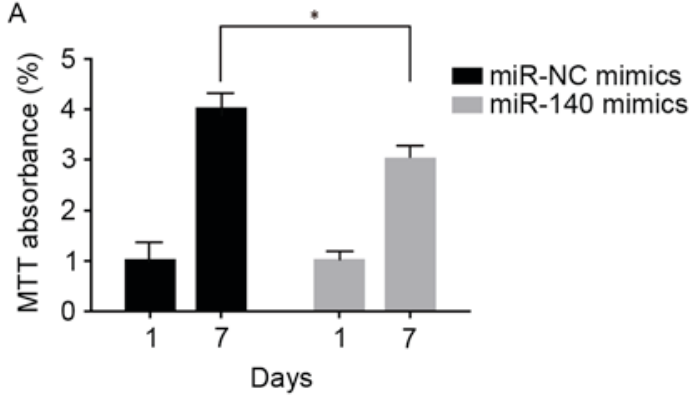

B

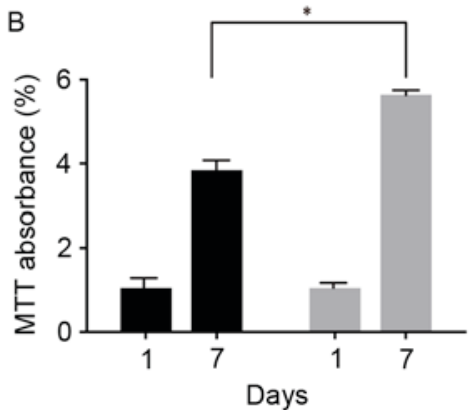

miR-NC inhibitor miR-140 inhibitor

Figure 5. Cell viability of C3H10T1/2 mesenchymal stem cells following the (A) overexpression and (B) inhibition of miR-140. * $<<0.05$, with comparisons indicated by brackets. miR, microRNA; NC, negative control.

A

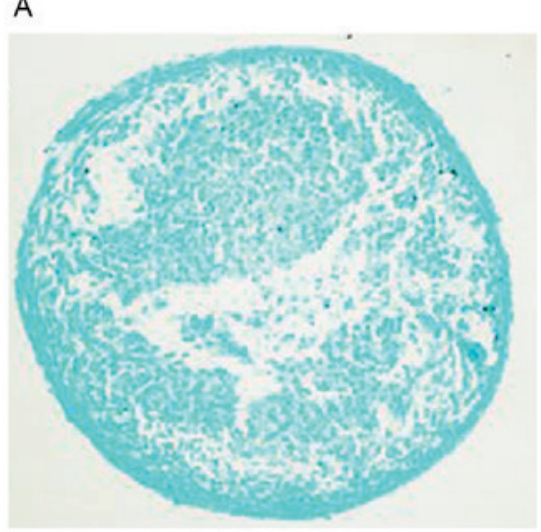

C

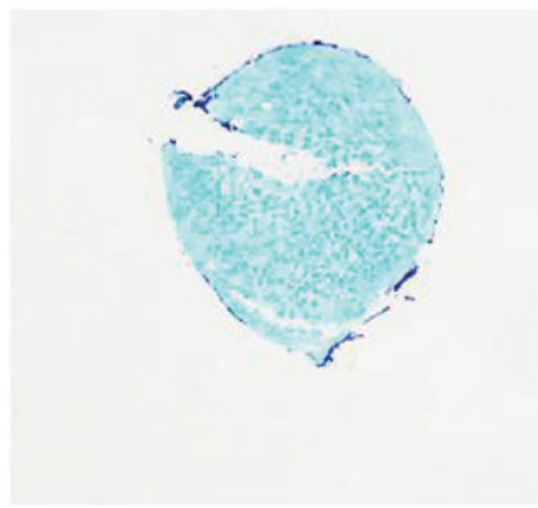

B

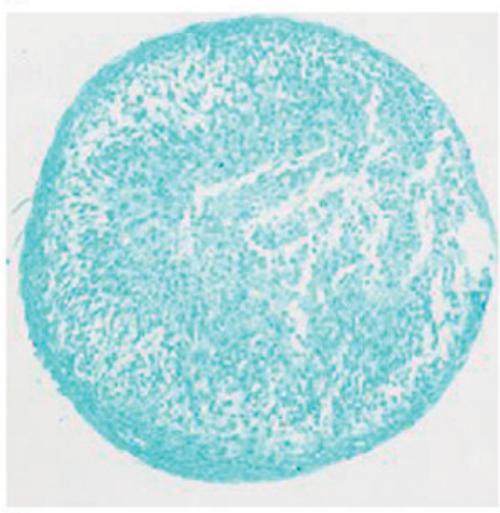

D

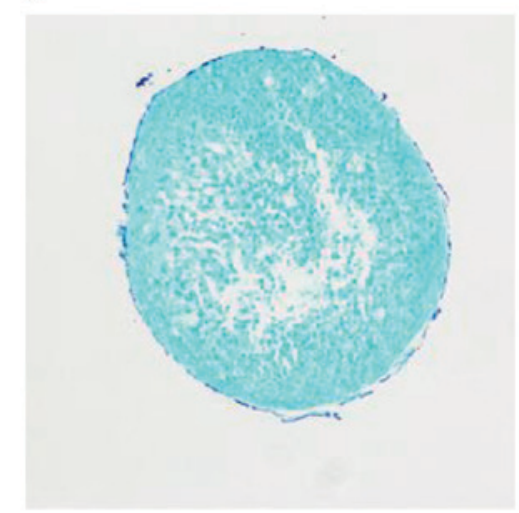

Figure 6. Alcian Blue staining in cell pellets generated by chondrogenic differentiation following induction of C3H10T1/2 mesenchymal stem cells for 7 days. Representative images of cell pellets treated with (A) miR-NC mimics, (B) miR-140 mimics, (C) miR-NC inhibitor and (D) miR-140 inhibitor. Magnification, x100. miR, microRNA; NC, negative control.

investigated whether the level of CXCL12 expression was affected by miR-140 activation/inhibition in TGF- $\beta 3$-induced C3H10T1/2 MSCs.

Based on our previous study of cell pellets generated from TGF- 33 -induced chondrogenic differentiation in C3H10T1/2 MSCs (6), it was revealed that CXCL12 was markedly decreased when miR-140 is overexpressed, however, it increased when miR-140 expression was inhibited. In addition, CXCL12 expression levels declined as the length of experiment increased in the control and experimental groups. The results of the present study combined with those of our previous study (6), suggest that miR-140 may take part in the formation of cell pellets by regulating CXCL12. However, it is unknown which process
miR-140 regulates, C3H10T1/2 MSC proliferation or differentiation.

In the present study $\mathrm{C} 3 \mathrm{H} 10 \mathrm{~T} 1 / 2 \mathrm{MSC}$ viability was detected, and the results revealed that following transfection with miR-140 mimics, it was significantly reduced when compared with the miR-NC group. However, C3H10T1/2 MSC proliferation was significantly promoted following miR-140 mimics transfection. Alcian blue staining identifies the characteristic extracellular matrix GAGs secreted by chondrocytes (28). In the present study, GAG synthesis was also measured by alcian blue staining and no visible difference in GAG synthesis was observed between the groups with overexpression or inhibition of miR-140 at 7 days following TGF- $\beta 3$-induced chondrogenic differentiation. 
The present study investigated the biological effects of miRNA-140 on CXCL12 and C3H10T1/2 MSC proliferation/differentiation based on our previous study (6). Collectively, the results indicate that prior to progression in TGF- $\beta 3$-induced chondrogenesis, C3H10T1/2 MSC proliferation may be effectively upregulated by promoting CXCL12, which could be induced by inhibiting miRNA-140 expression. The results highlight the potential role of miRNA-140 in future clinical therapies to treat cartilage defection via CXCL12 targeting. Future studies will further investigate the function and precise regulatory mechanism of miRNA-140.

\section{Acknowledgements}

The present study was financially supported by the National Basic Research Program of China (973 Program; grant no. 2012CB619105).

\section{References}

1. Redman SN, Oldfield SF and Archer CW: Current strategies for articular cartilage repair. Eur Cell Mater 9: 23-32, 2005.

2. Xian CJ and Foster BK: Repair of injured articular and growth plate cartilage using mesenchymal stem cells and chondrogenic gene therapy. Curr Stem Cell Res Ther 1: 213-229, 2006.

3. Ji YH, Ji JL, Sun FY, Zeng YY, He XH, Zhao JX, Yu Y, Yu SH and $\mathrm{Wu} \mathrm{W}$ : Quantitative proteomics analysis of chondrogenic differentiation of C3H10T1/2 mesenchymal stem cells by iTRAQ labeling coupled with on-line two-dimensional LC/MS/MS. Mol Cell Proteomics 9: 550-564, 2010.

4. Tang QQ, Otto TC and Lane MD: Commitment of C3H10T1/2 pluripotent stem cells to the adipocyte lineage. Proc Natl Acad Sci USA 101: 9607-9611, 2004

5. Son HE, Kim TH and Jang WG: Curculactones A and B induced the differentiation of C3H10T1/2 and MC3T3-E1 cells to osteoblasts. Bioorg Med Chem Lett 27: 1301-1303, 2017.

6. Wa Q, Gao M, Dai X, Yu T, Zhou Z, Xu D and Zou X: Induction of chondrogenic differentiation of mouse embryonic mesenchymal stem cells through an in vitro pellet model. Cell Biol Int 39: 657-665, 2015.

7. Megosh HB, Cox DN, Campbell C and Lin H: The role of PIWI and the miRNA machinery in Drosophila germline determination. Curr Biol 16: 1884-1894, 2006.

8. Park JK, Liu X, Strauss TJ, McKearin DM and Liu Q: The miRNA pathway intrinsically controls self-renewal of Drosophila germline stem cells. Curr Biol 17: 533-538, 2007.

9. Wang Y, Medvid R, Melton C, Jaenisch R and Blelloch R: DGCR8 is essential for microRNA biogenesis and silencing of embryonic stem cell self-renewal. Nat Genet 39: 380-385, 2007.

10. Luzi E, Marini F, Sala SC, Tognarini I, Galli G and Brandi ML: Osteogenic differentiation of human adipose tissue-derived stem cells is modulated by the miR-26a targeting of the SMAD1 transcription factor. J Bone Miner Res 23: 287-295, 2008.

11. Guerit D, Brondello JM, Chuchana P, Philipot D, Toupet K, Bony C, Jorgensen C and Noël D: FOXO3A regulation by miRNA-29a Controls chondrogenic differentiation of mesenchymal stem cells and cartilage formation. Stem Cells Dev 23: 1195-1205, 2014

12. Guerit D, Philipot D, Chuchana P, Toupet K, Brondello JM, Mathieu M, Jorgensen C and Noël D: Sox9-regulated miRNA-574-3p inhibits chondrogenic differentiation of mesenchymal stem cells. PLoS One 8: e62582, 2013.
13. Huang C, Geng J, Wei X, Zhang R and Jiang S: MiR-144-3p regulates osteogenic differentiation and proliferation of murine mesenchymal stem cells by specifically targeting Smad4. FEBS Lett 590: 795-807, 2016.

14. Huang K, Fu J, Zhou W, Li W, Dong S, Yu S, Hu Z, Wang H and Xie Z: MicroRNA-125b regulates osteogenic differentiation of mesenchymal stem cells by targeting $\operatorname{Cbf} \beta$ in vitro. Biochimie 102: 47-55, 2014.

15. Liu Y, Zhang ZC, Qian SW, Zhang YY, Huang HY, Tang Y, Guo L, Li X and Tang QQ: MicroRNA-140 promotes adipocyte lineage commitment of $\mathrm{C} 3 \mathrm{H} 10 \mathrm{~T} 1 / 2$ pluripotent stem cells via targeting osteopetrosis-associated transmembrane protein 1 . J Biol Chem 288: 8222-8230, 2013.

16. Schrader AJ, Lechner O, Templin M, Dittmar KE, Machtens S, Mengel M, Probst-Kepper M, Franzke A, Wollensak T, Gatzlaff $\mathrm{P}$, et al: CXCR4/CXCL12 expression and signalling in kidney cancer. Br J Cancer 86: 1250-1256, 2002.

17. Blanchet $X$, Langer $M$, Weber $C$, Koenen $R R$ and von Hundelshausen P: Touch of chemokines. Front Immunol 3: 175,2012

18. Hosogane N, Huang Z, Rawlins BA, Liu X, Boachie-Adjei O, Boskey AL and Zhu W: Stromal derived factor-1 regulates bone morphogenetic protein 2-induced osteogenic differentiation of primary mesenchymal stem cells. Int J Biochem Cell Biol 42: 1132-1141, 2010

19. Liu C, Weng Y, Yuan T, Zhang H, Bai H, Li B, Yang D, Zhang R, He F, Yan S, et al: CXCL12/CXCR4 signal axis plays an important role in mediating bone morphogenetic protein 9-induced osteogenic differentiation of mesenchymal stem cells. Int J Med Sci 10: 1181-1192, 2013

20. Pfeffer S and Voinnet O: Viruses, microRNAs and cancer. Oncogene 25: 6211-6219, 2006.

21. Taft RJ, Pang KC, Mercer TR, Dinger M and Mattick JS: Non-coding RNAs: Regulators of disease. J Pathol 220: 126-139, 2010.

22. Miyaki S, Nakasa T, Otsuki S, Grogan SP, Higashiyama R, Inoue A, Kato Y, Sato T, Lotz MK and Asahara H: MicroRNA-140 is expressed in differentiated human articular chondrocytes and modulates interleukin-1 responses. Arthritis Rheum 60: 2723-2730, 2009

23. Swingler TE, Wheeler G, Carmont V, Elliott HR, Barter MJ, Abu-Elmagd M, Donell ST, Boot-Handford RP, Hajihosseini MK, Münsterberg A, et al: The expression and function of microRNAs in chondrogenesis and osteoarthritis. Arthritis Rheum 64: 1909-1919, 2012.

24. Karakus S, Bagci B, Bagci G, Sancakdar E, Yildiz C, Akkar O and Cetin A: SDF-1/CXCL12 and CXCR4 gene variants, and elevated serum SDF-1 levels are associated with preeclampsia. Hypertens Pregnancy: 1-7, 2016 (Epub ahead of print).

25. Nagasawa T, Hirota $S$, Tachibana $K$, Takakura N, Nishikawa $S$, Kitamura Y, Yoshida N, Kikutani H and Kishimoto T: Defects of B-cell lymphopoiesis and bone-marrow myelopoiesis in mice lacking the CXC chemokine PBSF/SDF-1. Nature 382: 635-638, 1996.

26. Ratajczak MZ, Zuba-Surma E, Kucia M, Reca R, Wojakowski W and Ratajczak J: The pleiotropic effects of the SDF-1-CXCR4 axis in organogenesis, regeneration and tumorigenesis. Leukemia 20: 1915-1924, 2006

27. Kanbe K, Takemura T, Takeuchi K, Chen Q, Takagishi K and Inoue K: Synovectomy reduces stromal-cell-derived factor-1 (SDF-1) which is involved in the destruction of cartilage in osteoarthritis and rheumatoid arthritis. J Bone Joint Surg Br 86: 296-300, 2004

28. Björnsson S: Simultaneous preparation and quantitation of proteoglycans by precipitation with alcian blue. Anal Biochem 210 : 282-291, 1993. 